\title{
Fungal and other spore counts as predictors of admissions for asthma in the Trent region
}

\author{
R Newson, D Strachan, J Corden, W Millington
}

\begin{abstract}
Objectives-The importance of airborne fungal and other spores in provoking asthma attacks is uncertain. Panel studies have generated evidence that suggests a link between outdoor spore counts and severity of asthma. There have been no population based time series studies relating outdoor exposure to spores with incidence of attacks of asthma.

Methods-Outcomes were hospital admissions for asthma on $\mathbf{2 0 0 2}$ days during 1987-94, for children and adults in the Trent region of England. Predictors were daily counts of 25 spore taxa from volumetric traps in Derby on the same and previous day. Admissions for asthma were adjusted for weekly, seasonal, and longer term trends by log linear autoregressive models. Spore counts on 6 days of asthma epidemics were also examined.
\end{abstract}

Results-When spore counts for individual taxa were analysed as quantitative variables, two positive and two negative correlations (out of a possible 100) were significant at the $5 \%$ level. When spore counts were dichotomised at the 90th percentile, one negative and eight positive correlations (out of 100) were significant at the $5 \%$ level. All significantly positive associations related to admissions among children, but none involved the total spore count. However, total spores were above the 90th percentile on four of the six epidemic days (odds ratio (OR) $9.92,95 \%$ confidence interval ( $95 \%$ CI) 1.41 to 109.84), but epidemics occurred on only four of 343 days with high total moulds.

Imperial College School of Medicine, London, UK

R Newson

Section of

Epidemiology,

Department of Public

Health Sciences,

St George's Hospital

Medical School,

Cranmer Terrace,

London SW17 0RE, UK

D Strachan

Midlands Asthma and Allergy Research Association, Derby,

UK

J Corden

W Millington

Correspondence to:

Dr David Strachan

d.strachan@sghms.ac.uk

Accepted 6 July 2000

possibility that fungal spores may allergic asthma has been recognised for over 30 years, ${ }^{1}$ but epidemiological studies have generally concentrated on the relation between respiratory symptoms to indoor exposure to moulds, especially in the home. ${ }^{2}$ The prevalence of mould allergy is difficult to determine due to difficulties in producing standardised allergen extracts, ${ }^{3}$ but sensitisation to mould extracts occurs in a few asthmatic patients of all ages, ${ }^{4-8}$ usually in association with reactions to other aeroallergens - such as pollen, house dust mites, and animal danders. ${ }^{5}$

Sensitisation to the outdoor mould Alternaria alternata has been implicated as a major risk factor for fatal asthma attacks in Chicago, USA. ${ }^{9}$ This may simply reflect a common association with severe asthma, but in Chicago, deaths from asthma at ages 5-34 years occur about twice as commonly on days with a high total mould spore count $\left(>1000\right.$ spores $\left./ \mathrm{m}^{3}\right)$ as on days with lower spore counts. ${ }^{10}$

Panel studies of asthmatic patients report inconsistent findings relating symptom severity with concentrations of mould spores in outdoor air. ${ }^{11-16}$ Some studies have found an association with total counts of mould spores, ${ }^{11} 14$ whereas others have reported a correlation between severity indices and specific groups or species, including basidiospores $^{14-16}$; Cladosporium ${ }^{13}$; Alternaria ${ }^{16}$; and Didymella exitialis. ${ }^{12}$ The release of spores of Didymella and Sporobolomyces in response to rapid changes in humidity was suggested as a possible explanation for an outbreak of asthma attacks after a thunderstorm around Birmingham, United Kingdom, in July $1983 .{ }^{17}$ However, subsequent work has suggested grass pollen as a more likely cofactor. ${ }^{18}$

No population based studies have investigated the temporal relation between non-fatal asthma attacks and counts of spores of outdoor moulds. In this paper, we examine whether, other things being equal, hospital admissions for asthma are more common on days with, or immediately after, high spore counts. In practice, other things are not equal. Admissions for asthma have an annual cycle, both in adults and (even more spectacularly) in children, when there are peaks after the end of school holidays. ${ }^{19}$ There is also a weekly cycle, peaking on Monday. Between years, there is also a long term trend. This was detailed for the Trent region in a previous report. ${ }^{20}$ These predictable fluctuations must be allowed for in the search for short term epidemics as might be caused by fungal spores. The importance of fungal spores can therefore be measured by defining a measure of excessive admissions for asthma, given the year and season, and finding whether higher spore counts occur with excessive admissions for asthma. This report aims to do this.

\section{Methods}

ADMISSIONS FOR ASTHMA DATA

Acute admissions for asthma for the Trent Regional Health Authority (regional health authority) were extracted from the hospital 
episodes system, as described previously. ${ }^{20}{ }^{21}$ These data contained daily counts of patients, where a day is taken as the interval from midnight to midnight on Greenwich mean time (GMT). For each of the 2435 days from 1 July 1987 to 28 February 1994, two sets of admissions for asthma were recorded, one for patients aged $0-14$ years, the other for patients aged 15 years or over. These two separate series were defined because of the radically different pattern of annual cycles in the two age groups. Mean daily admissions for asthma were 10.7 a day in the $0-14$ year group and 10.6 in patients aged 15 or over.

\section{SPORE COUNT DATA}

These were collected from a succession of volumetric spore traps ${ }^{22}$ sited in Derby. Data from 1987 to 1991 were collected with a Morrow-Brown volumetric spore trap..$^{23}$ From 1987 to 1990 , this was sited on a second storey roof $10 \mathrm{~m}$ above ground level in central Derby. In 1990, building developments caused a site change to the roof of the Mickleover site of Derby University, in a suburb about $4 \mathrm{~km}$ south west of central Derby, $100 \mathrm{~m}$ above sea level and $10 \mathrm{~m}$ above ground level. In 1991, the Morrow-Brown trap was replaced by a new volumetric trap (Burkard, Rickmansworth, UK). Either a daily slide or a 7 day drum trap was used, and mounting and staining techniques followed the local standard methods. ${ }^{23}$ Spores were identified by taxon and counted over one microscope field along the length of the microscope slide, and the count was multiplied by the appropriate factor to yield the mean spore count $/ \mathrm{m}^{3}$ of air for each taxon on each day. The day corresponding to a given date is defined as the interval from 0000 GMT on that date to 0000 GMT on the next date. Two ways were used for matching the days of the spore count data with the days of the hospital episode system data on admissions for asthma. These matched the hospital admissions with the spore count on the same day (a 0 day lag) and on the previous day (a 1 day lag).

Daily counts were available for 30 elementary spore taxa, mutually exclusive on any given day (table 1). All taxa are fungal, except for Actinomycetes (bacteria), Myxomycetes (slime moulds), algae, Pteridophytes (fern spores), and Pteridium (bracken). Series of spore counts were available with varying degrees of completeness. For all taxa, there were gaps in the series in the winter months from 1987-90, but from 1990-1, when year round recording began, spore counts in these months were low. As well as the 30 elementary taxa, three summary taxa were defined by summing subsets of the elementary taxa, with a view to defining a small number of predictors of initial interest (see footnote to table 1).

STATISTICAL METHODS

These were based on the log linear autoregression model described elsewhere. ${ }^{20}$ This was a

Table 1 Daily spore counts recorded at Derby, 1987-96

\begin{tabular}{|c|c|c|c|c|c|}
\hline \multirow[b]{2}{*}{ Taxon name } & \multicolumn{3}{|c|}{1 fuly 1987 to 28 February 1994} & \multicolumn{2}{|c|}{$\begin{array}{l}1 \text { Fanuary } 1991 \text { to } 31 \text { December } \\
1996\end{array}$} \\
\hline & $\begin{array}{l}\text { Daily } \\
\text { counts }\end{array}$ & $\begin{array}{l}\text { Positive } \\
\text { counts }\end{array}$ & $\begin{array}{l}\text { High } \\
\text { counts }\end{array}$ & $\begin{array}{l}\text { Mean } \\
\text { count }\end{array}$ & $\begin{array}{l}\text { 90th } \\
\text { percentile* }\end{array}$ \\
\hline \multicolumn{6}{|l|}{ Elementary taxa: } \\
\hline Alternaria & 2010 & 1321 & 190 & 65.47 & 160 \\
\hline Aspergillus or Penicillium type $\dagger$ & 2010 & 1983 & 228 & 140.38 & 300 \\
\hline Cladosporium & 2010 & 1994 & 244 & 2806.49 & 8156 \\
\hline Epicoccum & 2010 & 869 & 297 & 9.12 & 30 \\
\hline Botrytis & 2010 & 1542 & 271 & 46.83 & 132 \\
\hline Sporobolomyces & 2010 & 2006 & 360 & 3170.21 & 6565 \\
\hline Tilletiopsis & 2010 & 2002 & 392 & 1707.39 & 4095 \\
\hline Coloured basidiospores & 2010 & 1887 & 214 & 264.09 & 692 \\
\hline Miscellaneous hyaline basidiospores $\ddagger$ & 2010 & 1964 & 222 & 521.38 & 1416 \\
\hline Ustilago & 2010 & 1068 & 226 & 64.66 & 125 \\
\hline Rusts & 2010 & 1222 & 223 & 15.86 & 50 \\
\hline Didymella & 2010 & 1649 & 341 & 376.20 & 700 \\
\hline Erysiphe & 2010 & 1498 & 316 & 25.85 & 65 \\
\hline Leptosphaeria & 2010 & 1921 & 272 & 116.17 & 312 \\
\hline Miscellaneous 1-septate ascospores $\$ & 2010 & 1649 & 170 & 49.77 & 125 \\
\hline Other ascospores & 2010 & 1709 & 153 & 98.78 & 254 \\
\hline Torula & 2010 & 610 & 297 & 3.14 & 10 \\
\hline Algal group & 2010 & 1113 & 220 & 9.64 & 25 \\
\hline Hyaline indeterminates & 2010 & 1999 & 506 & 612.29 & 1395 \\
\hline Pleospora & 2010 & 287 & 111 & 3.63 & 10 \\
\hline Myxomycetes & 2010 & 114 & 114 & 1.00 & 1 \\
\hline Drechslera & 2010 & 223 & 223 & 0.58 & 17 \\
\hline Polythrinchium & 2010 & 484 & 289 & 2.75 & 8 \\
\hline Fern spores & 2010 & 46 & 46 & 0.07 & 1 \\
\hline Entomophthora & 420 & 129 & 62 & 4.84 & 15 \\
\hline \multicolumn{6}{|l|}{ Summary taxa $a^{\star \star}:$} \\
\hline Total ascospores & 2010 & 1980 & 307 & 644.53 & 1400 \\
\hline Total hyaline basidiospores or ballistospores & 2010 & 2006 & 367 & 5398.97 & 11865 \\
\hline Total moulds & 2010 & 2010 & 343 & 10101.00 & 23790 \\
\hline
\end{tabular}

^High counts defined as $>90$ th percentile for the period of continuous recording (1 January 1991 to 31 December 1996) tComprising Aspergillus, Penicillium and other mutually indistinguishable genera.

†Excluding Sporobolomyces and Tilletiopsis.

§Excluding Didymella.

ॠRecorded from 1 January 1993 (all other taxa started 31 March 1987).

$\star \star$ The three summary taxa are: total ascospores (Didymella + Leptosphaeria + Pleospora + miscellaneous 1 -septate ascospores + other ascospores); total hyaline basidiospores and ballistospores (Sporobolomyces + Tilletiopsis + miscellaneous hyaline basidiospores); total moulds (the total of all spore counts except algal group, Myxomycetes, Actinomycetes, fern spores and Pteridium (non-fungal), and Humicola, Entomophthora and miscellaneous smuts (not available from 1987)). 
statistical model used to forecast the number of admissions for asthma expected in a particular regional health authority in each age group on each day, before spore counts were considered. A separate model was fitted to the admissions data for each age group in the Trent regional health authority, taking into account weekly and annual cycles, longer term trends, and the short term (autoregressive) tendency of numbers of admissions for asthma to be similar to those for the previous 8 days. For each day, a standardised residual was defined, roughly equal to the relative excess of observed admissions for asthma compared with those expected (or forecast), expressed in units of the coefficient of variation (CV).

The standardised residuals were included in analyses in two ways. Firstly, the ability of high spore counts to predict high residuals was measured with Somers' $D .{ }^{24}$ This variable compares two conditional probabilities: given that 2 days have unequal spore counts, Somers' $D$ is the probability that the day with the higher spore count has the higher standardised residual for admissions for asthma, minus the probability that the day with the higher spore count has the lower standardised residual. It has the advantage that it can be applied both to continuous and to dichotomous exposure variables. For a dichotomous exposure, the statistical significance of Somers' $D$ is equivalent to that of the Mann-Whitney $U$ test. For continuous data it is equivalent to a test of rank correlation. In these analyses, spore counts were entered in two ways, directly as quantitative variables and after conversion to binary variables, indicating whether or not the count was high in the sense of attaining (or exceeding) the value of a threshold. For each taxon, the threshold was either one or the 90th percentile of counts recorded for that taxon in years from 1991 onwards, whichever was greater (table 1).

Secondly, attention was focused on 6 days of spectacular epidemics, identified elsewhere ${ }^{20}$ as days on which the standardised residual, for at least one age group, was over $4 \mathrm{CV}$ units. These epidemics occurred on 30 April 1988 and 15 September 1990 in the 0-14 age group, and on 23 August 1987, 14 June 1989, 23 July 1989, and 4 August 1991 in the age group 15 or more. Odds ratios were calculated (with exact $95 \%$ confidence intervals (95\% CIs)) to estimate the relative risks of epidemics between days of high and low spore counts for each taxon, together with $\mathrm{p}$ values for Fisher's exact test. Also, for each epidemic and taxon, the triplet of three spore counts corresponding to the epidemic day, and the days 7 days before and after it, were compared.

All analyses were carried out with the SAS system $^{25}$ or Stata software. ${ }^{26}$

The number of significance tests was large, because of the number of available taxa and the multiple age groups, lag periods, and methods of comparison. The number of alternative statistical procedures for dealing with multiple significance tests is also large, but nearly all use minimum $\mathrm{p}$ values. ${ }^{27}$ Tables 2 and 3 therefore show the minimum $\mathrm{p}$ values for all available elementary and summary taxa in each analysis.

\section{Results}

SPORE COUNTS

Table 1 summarises the spore counts for July 1987 to February 1994 inclusive, corresponding to the time series of hospital admissions, and the thresholds for high counts, derived from the period January 1991 to December 1996, the period of recording all year round at Derby. Note that some taxa have a lot more or less than $10 \%$ of their available counts in the high category. The excesses exist because, from 1987 to 1990 , winter counts, which usually would have been low, were not available. The deficiencies exist because, for some taxa, the 90th percentile is zero, so a threshold of one was used instead.

RELATION BETWEEN ADMISSIONS FOR ASTHMA AND HIGH AND LOW SPORE COUNTS

Table 2 summarises the analyses of standardised residuals from the time series of admissions for asthma relative to spore counts for each taxon, expressed as Somers' $D$ (indicating the direction of the association) and the corresponding $\mathrm{p}$ value (indicating its significance). Results are shown for spore counts on the same day, and on the previous day, dichotomised into low and high categories on the left, and with spore counts treated as continuous variables on the right. The number of days contributing to these statistics is 2002 (2010 minus the first 8 days which had no forecast counts) for all taxa except Entomophthora, which started to be recorded late (419 days).

When spore counts for individual taxa were analysed as quantitative variables, two positive and two negative correlations (out of a possible 100) were significant at the $5 \%$ level: close to what would be expected by chance alone. The significant positive associations were both with residual categories in the younger age group: miscellaneous hyaline basidiospores (age 0-14, lag $0, p=0.014$ ) and other ascospores (age $0-14$, lag $0, p=0.043$ ). Significant inverse associations were found with coloured basidiospores (age $\geqslant 15$, lag $0, p=0.019$ ) and Drechslera (age $\geqslant 15$, lag $1, \mathrm{p}=0.023$ ).

When spore counts were dichotomised at the 90th percentile, there were more positive associations than expected by chance alone: one negative and eight positive correlations (out of 100) were significant at the $5 \%$ level. All the significant positive associations were in the younger age group, but none were significant at the $1 \%$ level. These were: miscellaneous hyaline basidiospores (age 0-14, lag 0, $\mathrm{p}=0.015$ ); Didymella (age 0-14, lag 0, $\mathrm{p}=0.028$ ); Leptosphaeria (age $0-14$, lag 0 , $\mathrm{p}=0.014$ ); other ascospores (age $0-14$, lag 0 , $\mathrm{p}=0.043$ ); total ascospores (age $0-14$, lag 0 , $\mathrm{p}=0.027$ ); Botrytis (age 0-14, lag 1, $\mathrm{p}=0.012$ ); other ascospores (age $0-14$, lag $1, \mathrm{p}=0.048$ ); and total ascospores (age 0-14, lag 1, $\mathrm{p}=0.017$ ). The only significant negative association was for Drechslera (age $\geqslant 15$, lag 1 , $\mathrm{p}=0.023)$.

The total mould spore count was not significantly associated with daily admissions for asthma in either age group in any of these analyses (minimum $\mathrm{p}=0.083$ ). 


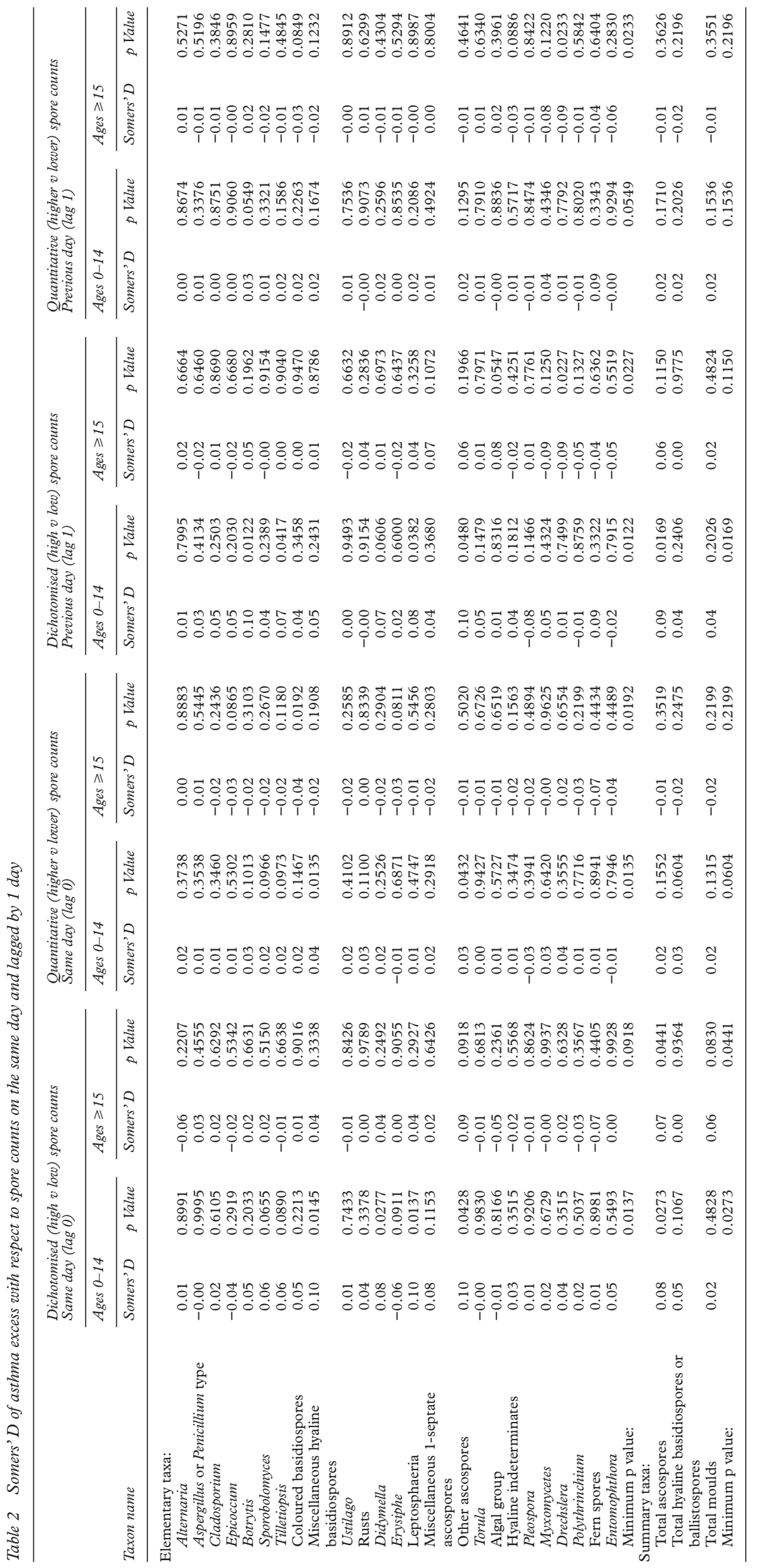




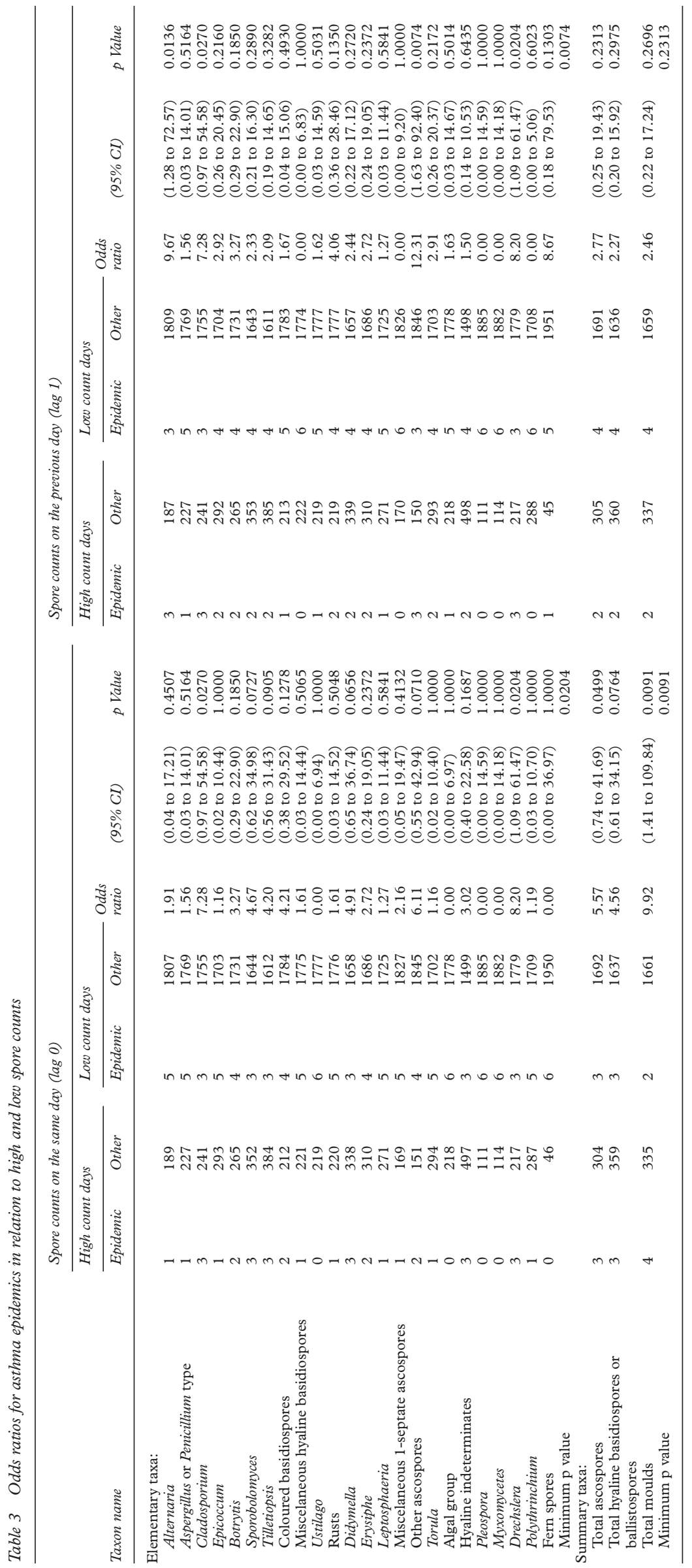


ODDS RATIOS FOR EPIDEMICS

There were six epidemics, all of which occurred on days with counts on the same and the previous day for all elementary taxa, except Entomophthora. Table 3 shows the relation between the epidemic days and high spore counts for each taxon, with 0 day and 1 day lags. Asthma epidemics were about 10 times more likely on a day with a high total mould spore count $(\mathrm{p}<0.01)$, but with wide $95 \%$ CIs for the odds ratio (1.4 to 109.8). Although the association of epidemics with total spore count on the previous day was weaker, there were significant associations (at the 5\% level) with counts of Alternaria, Drechslera, and other ascospores, when analysed with a 1 day lag.

COUNT TRIPLET ANALYSIS

A more quantitative test of the relation between epidemics of asthma and spore counts, which also controls for seasonal variation, was to compare spore counts on the epidemic day with those 7 days before and 7 days afterwards. In this case we have only six epidemics, and therefore no more than six triplets of counts for such an analysis. For three out of these six epidemics, the total spore count on the epidemic day was higher than either of the total spore counts 7 days before and after.

\section{Discussion}

These analyses are an attempt to assess the predictive power of spore count data, the availability of which was sometimes fragmentary, to predict admissions for asthma, the background variation of which was complicated. This is why the approach of residual analysis was chosen. This predictive power was measured in four different ways. Three of these have produced no more significant results than we might expect by chance, given the number of 95\% CIs that have been calculated. All four methods suggest that spore counts alone cannot be the basis of a public warning system without generating an extremely high rate of false alarms.

The first approach (table 2) dichotomised spore counts into high and low categories. If high spore counts precipitated asthma, then warnings might be issued to the public in the event of spore counts exceeding a danger threshold. The thresholds used here do not seem to be very powerful predictors, as when 1 day has a high spore count and 1 day has a low spore count, the high count day is not especially more likely to have a higher asthma excess than the low count day.

The second method (also shown in table 2) sought a correlation between admissions for asthma and spore counts across their full range, without giving an undue influence to tiny minorities of outlying counts. Somers' $D$ can be used to sense such a gradient without committing ourselves to a particular functional form for the exposure-response relation, the estimation of which would be highly affected by small numbers of extremely high spore counts.

The third approach (table 3) concentrates attention on spectacular epidemics, of which there were only six in the Trent regional health authority between July 1987 and February 1994. High total moulds on the same day predicted four of those six epidemics, but only four of 343 high spore days were associated with asthma epidemics. If we use a more stringent definition of high spore count (above the 99th percentile), the predictive power is one epidemic (in 1987) among 34 very high spore days.

The fourth way compares epidemic days with the days 1 week before and after, by analogy with similar methods used elsewhere on 55 epidemic episodes. ${ }^{20}$ This avoids the problem of seasonal confounding, asthma epidemics being more common in the summer when spore counts are generally higher, but is statistically much less powerful than comparisons that include all non-epidemic days (table 3 ).

A general problem with all these analyses is that of multiple comparisons. With over 20 taxa being tested, at least one will be significant at the $5 \%$ level, on average, just by chance, even if all null hypotheses are true and none of the taxa have any predictive value. Also, we tested each taxon up to eight times (two lags multiplied by four different statistical measures of predictive power), and split some analyses into two age groups. The overall pattern of results lacked consistency, except that all the significant positive associations occurred in the $0-14$ age group. Nevertheless, this comprehensive analysis of admissions for asthma relative to outdoor spore counts showed several positive associations which might form a basis for future work.

Causal relations were not convincingly found, but cannot be ruled out. For instance, it may be that mould spores are patchily distributed, so that a high count at Derby correlates poorly with aeroallergen concentrations over the rest of the Trent region, and asthma epidemics take place only when spores are abundant in all parts of the region. This possibility could be rectified by analysing data from a smaller and more densely populated area. However, we can conclude that outdoor spore counts measured at Derby do not seem to predict daily rates of admission for asthma in the Trent region as a whole sufficiently well to be the basis for a public warning system.

Another possibility is that spores cause asthma attacks only in combination with other factors, such as thunderstorms. ${ }^{28}$ This seems to be the case for grass pollen, ${ }^{21}$ but, to demonstrate this synergism convincingly, we had to combine data from several regions, many of which lack data on mould spores. Only 1 of the 6 epidemic days in Trent (23 August 1987) was associated with substantial local thunderstorm activity (on the previous day), so this interaction cannot be the explanation for most well defined epidemics. ${ }^{20}$ However, this thunderstorm on 22 August 1987 was associated with exceptionally high counts of Didymella spores, ${ }^{29}$ which may have played a part in that specific epidemic, as suggested for an earlier asthma epidemic in Birmingham. ${ }^{17}$

Measurements of air pollution were not available for the whole Trent region, but our results suggest that it is unlikely that mould 
spores are a major unmeasured confounding influence in other time series analyses relating outdoor air pollutants with frequency of asthma attacks. However, specific interactions between mould exposure and outdoor air pollutants were not considered in our analysis. Experimental chamber studies have raised the possibility that earlier exposure to gaseous air pollutants may decrease the threshold of response to grass pollen or house mite allergens, ${ }^{30-32}$ and the same might apply to fungal allergens. However, no evidence emerged from time series in London to support a synergistic interaction of pollens and pollutants in assessing rates of admission for asthma. ${ }^{33}$

The London analyses are currently being extended to include fungal aeroallergens and will seek to test specifically the significant relations which have emerged in Trent, as well as possible interactions between pollutants and aeroallergens.

This work was funded in part by a grant from the National Asthma Campaign for the admissions for asthma data retrieval, (MAARA) for the spore counts data collection.

1 Herxheimer H, Hyde HA, Williams DA. Allergenic asthma caused by fungal spores. Lancet 1966 ; i: $572-3$.

2 Verhoeff AP, Burge HA. Health risk assessment of fungi in home environments. Ann Allergy Asthma Immunol 1997;78: 544-54.

3 Horner WE, Helbling A, Salvaggio JE, et al. Fungal allergens. Clin Microbiol Rev 1995;8:161-79.

4 Beaumont F, Kauffman HF, de Monchy JG, et al. Volumetric aerobiological survey of conidial fungi in the north-eas Netherlands. Comparison of aerobiological data and skin tests with mould extracts in an asthmatic population. Allergy 1985;40:181-6.

5 Hendrick DJ, Davies RJ, D'Souza MF, et al. An analysis of skin prick reactions in 656 asthmatic patients. Thorax 1975;30:2-8

6 Koivikko A, Viander M, Lanner A. Use of the extended Phadebas RAST panel in the diagnosis of mould allergy in asthmatic children. Allergy 1994;49:460-5.

7 Lehrer SB, Hughes JM, Altman LC, et al. Prevalence of basidiomycete allergy in USA and Europe and its relationship to allergic respiratory symptoms. Allergy 1994;49:4605 .

8 Tariq SM, Matthews SM, Stevens M, et al. Sensitization to Alternaria and Cladosporium by the age of 4 years. Clin Exp Allergy 1996;26:794-8.

9 O'Halloren MT, Yunginger JW, Offord KP, et al. Exposure to an aeroallergen as a possible precipitating factor in respiratory arrest in young patients with asthma. $N \mathrm{Engl} \mathcal{F} \mathrm{Med}$ 1991;325:206-8
10 Targonski PV, Persky VW, Ramekrishnan V. Effect of environmental moulds on risk of death from asthma during the pollen season. F Allergy Clin Immunol 1995;95:955-61.

11 Beaumont F, Kauffman HF, Sluiter HJ, et al. Sequential sampling of fungal air spores inside and outside the homes of mould-sensitive asthmatic patients: a search for a relationship to obstructive reactions. Ann Allergy 1985;55: $740-6$.

12 Harries MG, Lacey J, Tee RD, et al. Didymella exitialis and ater summer asthma. Lancet 1985; i:1063-6.

13 Malling HJ. Diagnosis and immunotherapy of mould allergy. IV: relation between asthma symptoms, spore
counts and diagnostic tests. Allergy 1986;41:342-50.

14 Delfino RJ, Coate BD, Zeiger RS, et al. Daily asthma severity in relation to personal ozone exposure and outdoor fungal spores. Am f Respir Crit Care Med 1996;154:633-41.

15 Epton MJ, Martin IR, Graham P, et al. Climate and aeroallergen levels in asthma: a 12 month prospective study. Tho$\operatorname{rax}$ 1997;52:528-34.

16 Delfino RJ, Zeiger RS, Seltzer JM, et al. The effect of outdoor fungal spore concentrations on daily asthma severity. Environ Health Perspect 1997;105:622-35.

17 Packe GE, Ayres JG. Asthma outbreak during a thunderstorm. Lancet 1985;ii:199-204.

18 Knox RB. Grass pollen, thunderstorms and asthma. Clin Exp Allergy 1993;23:354-9.

19 Storr J, Lenney W. School holidays and admission with asthma. Arch Dis Child 1989;64:103-7.

20 Newson R, Strachan D, Archibald E, et al. Acute asthma epidemics, weather and pollen in England, 1987-94. Eur Respir F 1998;11:694-701.

21 Newson R, Strachan D, Archibald E, et al. The effect of thunderstorms and airborne grass pollen on acute asthma incidence in England. Thorax 1997;51:680-5.

22 Hirst JM. An automatic volumetric spore trap. Annals of Applied Biology 1952;39:257.

23 Morrow Brown H, Jackson FA. Aerobiological studies based in Derby. I. A simplified volumetric spore trap. Clin Allergy 1978;8:589-97.

24 Newson R. The snp15: somersd: confidence intervals for non-parametric statistics and their differences. College Station, TX: Stata, 2000. (Stata Technical Bulletin 2000 May; STB-55:47-55.)

25 SAS Institute SAS Language guide for personal computers, release 6.03 edition. Cary, NC: SAS Institute, 1988.

26 StataCorp. Stata statistical software: release 5.0. College Station, Texas: Stata Corporation, 1997.

27 Wright SP. Adjusted $\mathrm{p}$ values for simultaneous inference. Biometrics 1992;48:1005-13.

28 Morrow-Brown H, Jackson F. Asthma and the weather. Lancet 1983;i:630.

29 Corden J, Millington WM. Didymella ascospores in Derby. Grana 1993;33:104-7.

30 Molfino NA, Wright SC, Katz I, et al. Effect of low concentrations of ozone on inhaled allergen responses in asthmatic subjects. Lancet 1991;338:199-203.

31 Tunnicliffe WS, Burge PS, Ayres JG. Effect of domestic concentrations of nitrogen dioxide on airway responses to inhaled allergen in asthmatic patients. Lancet 1994;44: 1733-6.

32 Jorres R, Nowak D, Magnussen $H$. The effect of ozone exposure on allergen responsiveness in subjects with sthma and rhinitis. Am f Respir Crit Care Med 1996;153: $56-64$.

33 Anderson HR, Ponce de Leon A, Bland JM, et al. Air pollution, pollens and daily asthma admissions in London 1987-92. Thorax 1998;53:842-8. 